\title{
Mental models in nuclear emergency management
}

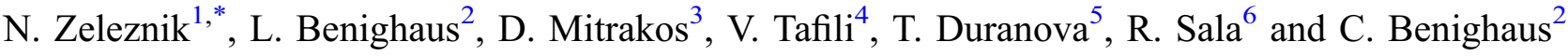 \\ ${ }^{1}$ EIMV-Milan Vidmar Electric Power Research Institute, Ljubljana, Slovenia. \\ 2 DIALOGIK - non-profit institute for communication and cooperation research, Stuttgart, Germany. \\ ${ }^{3}$ NTUA - National Technical University of Athens, Athens, Greece. \\ ${ }^{4}$ EEAE-Greek Atomic Energy Commission, Athens, Greece. \\ 5 VUJE-VUJE, a.s., Trnava, Slovak Republic. \\ ${ }^{6}$ CIEMAT-CISOT - Sociotechnical Research Centre, Barcelona, Spain.
}

\begin{abstract}
This paper reports on the research of mental models of uncertainties management in an emergency situation which was carried out in the framework of the European CONFIDENCE (COping with uNcertainties For Improved modelling and DEcision making in Nuclear emergenCiEs) Project. The methodology included the mapping of mental models among several emergency preparedness and response experts and then performing interviews based on structured protocol with lay people in five countries: Germany, Greece, Slovak Republic, Slovenia and Spain. The aim of these investigations was to trace the concepts and understandings of emergency preparedness and response and to identify possible gaps between experts and lay people. The article presents the main results of this research and suggestions for the improvement of EP \& R planning.
\end{abstract}

Keywords: emergencies and post-accident exposures / mental models / uncertainty management / radiation protection / experts / lay people

\section{Introduction}

Emergency Preparedness and Response (EP \& R) plans (IAEA, 2015) are prepared for many nuclear or radiological threats at different levels: national, regional, local, off-site, onsite, for individual organization, for facilities etc. All these plans are usually prepared by responsible authorities/institutions. Ideally, these documents should consider all appropriate information, including relevant uncertainties and public concerns in order to more effectively address the information needs of the possibly affected public in case of a nuclear or radiological accident.

In the CONFIDENCE (COping with uNcertainties For Improved modelling and DEcision making in Nuclear emergenCiEs) project (Raskob et al., 2020) which is aimed to understand, reduce and cope with the uncertainties in modelling and predictions of emergencies, the consideration of important social, ethical and communication aspects of emergency management is also included to investigate how stakeholders at various levels deal with uncertainty in their decision-making processes. The research on the EP \& R management mental models was performed as part of the socio-psychological study of understanding, processing and

\footnotetext{
*Corresponding author: nadja.zeleznik@eimv.si
}

the management of uncertainties with the aim to support and improve communication between involved stakeholders, and in particular potentially affected population.

The research was based on the mental model approach developed by Morgan and co-workers on risk perceived activities (Morgan et al., 2002) in which systematic analysis of what people believe and what information they need to make a decision was applied to the emergency management in case of nuclear or radiological accident (Zeleznik et al., 2019). The mental models of lay people ${ }^{1}$ for the emergency management are influenced by many factors, among which intuition and emotions, personal interest and involvement in the topic, existing widespread images (cultural icons) and interpretations (social representations), (mis)understanding of scientific facts, educational background, access to and understanding of information, credibility of information and communication processes, trust in information sources and communication partners, and more broadly, confidence in the governance of ionizing radiation risks. All these factors are inputs for forming of own representations - mental models which are constantly being (re/mis)interpreted, and internalized into explicit or

\footnotetext{
${ }^{1}$ Defined as persons who do not have specialized or professional knowledge of a subject: here, emergency planning and response of nuclear and radiological accident and risk associated to ionizing radiation.
} 
latent insights which, in turn, feed into renewed mental models.

By comparing the emergency response in current EP \& R plans which are developed by experts with lay people's mental models, possible gaps, misunderstandings, misconceptions and uncertainties can be revealed. Such information can serve as a basis for the future activities of competent authorities to improve the communication and the emergency plans to better fulfil expectations and needs of the population. The objectives of the research were to address the following questions:

- What are the mental models present within the potentially affected public regarding emergency management and associated uncertainties?

- What are the differences, gaps, misunderstandings and perceptions in the public compared with the ones provided by experts in the field?

- What are the similarities and differences on mental models between the countries in which the investigation took place?

- What lessons learned from the performed investigation can be extracted and what findings can be introduced in the improved communication and activities?

\section{Method for mental model investigation}

Mental models are cognitive schemes through which people explain individual processes or phenomena in which they are participating (Morgan et al., 2002). Mental models are incomplete, limited and fragmentary, usually wrong, contradictory and inconsistent, not scientifically founded. Because of that they are unstable and are evolving, as people forget details and are mixing old and new information. Mental models do not have clear and firm boundaries, different models are mixed and changed, are limited and enable simplified interpretation of complex processes.

For this study, the mental model approach was used for the investigation of uncertainty management in an emergency situation in case of nuclear or radiological accident. The focus of the investigation was on how plans are developed including what is the associated risk, what are the typical elements of plans and what protective measures are foreseen. In addition, issues of information, notification and trust were analysed. The research was performed in several stages:

- firstly, the expert model was created, based on the available expert knowledge of emergency preparedness and management, its planning, international recommendations and guidelines, and improvements based on experiences. The discussions with several experts from different countries (France, Germany, Ireland, Slovenia) helped to point out also major uncertainties of emergency management and check the consistency of general EP \& R;

- secondly, mental models of lay people (15-20 individuals per country, 84 in total) were obtained through the individual open-ended interviews following the prepared protocol, eliciting people's beliefs about the risk, expressed in their own terms, the understanding of protective measures and their expectations about information dissemination. The responses were analysed in terms of how well these mental models correspond to the expert models;
- thirdly, based on captured beliefs expressed in open-ended interviews and in expert models, the main differences were pointed out and the risk communication was developed and evaluated in support to the EP \& R management, especially in the field of identifying the uncertainties.

The mental model research was conducted in various national contexts (Germany, Greece, Slovenia, Slovak Republic and Spain) and enables the assessment of differences between countries and the relevant nuclear context and other sociocultural background. The countries involved in the investigation have different nuclear experiences, some with a long history of nuclear energy production and nuclear power plants operation (Germany, Spain, Slovak Republic, Slovenia), some of them are non-nuclear countries (Greece) and some are now in a nuclear phase-out (Germany). There is obviously also different sociocultural context relevant for involved countries; however, all countries have to be prepared for a nuclear or radiological emergency and the national approaches are similar as they comply with international recommendations and guidelines, like those of IAEA or HERCA/WENRA.

\section{Results of mental model investigation}

\subsection{Expert models}

The expert EP \& R model was created on the basis of available expert knowledge of emergency preparedness and response for the management of a radiological or nuclear accident. The expert model is an attempt to systematically pool in everything known or believed by the community of experts that is relevant for the area and risk decisions the audience faces. Analyses of national EP \& R plans were performed in order to obtain the information what is the concept of emergency management, what is included and how different areas are addressed. In addition, the discussions with several experts from different countries (Ireland, Slovenia, France) were performed to obtain the information on the approach to the preparedness and response, topics which should be covered in plans, which then determine the response in emergency and post-accident situations, from the early phase to recovery. The participants were asked to briefly describe the structure of EP \& R plans, what is most important for individual elements and what uncertainties could be associated with actions/activities/topics within different EP \& R areas.

The EP \& R plans for nuclear and radiological accidents usually include different topics and cover all different possible accidents in nuclear and radiation facilities in the country, but also nuclear and radiological accidents abroad with a potential impact on the country, and other radiological accidents involving ionising radiation sources. They are based on threat and risk assessments which consider all different nuclear and radiological accidents with a major release of radioactive substances into the environment or the irradiation of people with precise descriptions, possible reasons for accidents, their probability, level of threat, course and possible extent of the accidents, identification of endangered inhabitants, as well as possible consequences and plans for protection measures. The important part of EP \& R plans is notification and warning with responsibilities, governance and management with a description of tasks for all official bodies. 
The discussions with several experts from different countries revealed that the basic elements of EP \& R plan are very similar and universal. The differences occur due to country specific situations. One particular case is a situation without nuclear power plant in operation, where all related activities for NPP accident management in the country are not part of the plans, although planning is adopted for situation of NPP accident abroad. Fewer differences occur between plans for countries with many nuclear facilities or with only one nuclear power plant. However, differences were observed between the provisions on zones, reference levels, intervention levels and similar. The differences between countries are resulted, for example, from different government organizational structures, but what is relevant almost for all is the fact that civil protection or disaster protection authorities with inter-ministerial committee are the bodies in charge for response, and not the nuclear safety or radiation protection regulatory bodies. This kind of organization requires very good communication between all stakeholders to ensure effective decision making. In addition, a very large number of institutions and bodies involved represents a challenge for effective implementation of protective measures.

The experts also pointed out several areas as source of uncertainties in nuclear or radiological emergency that need to be properly addressed:

- the knowledge on ionizing radiation, consequences, associated hazard and real impact is relatively low within institutions and services foreseen to manage the emergency situation and therefore training and education would be needed;

- the development of an accident is quite unpredictable, like what meteorological factors have to be used for modelling, how the radioactive plume will be dispersed and where radioactive material will be deposited; therefore, it is very difficult to foresee the preventive measures;

- there is a potential threat of a radiological impact of an accident on the areas which are foreseen for the relocation of population during the implementation of protective measures; therefore, these areas could not be used for that purpose;

- there is an uncertainty in how people would actually react in nuclear emergency: would they follow the assumptions from EP \& R plans, for instance, to evacuate themselves without children who would be taken care of at schools, would they follow the evacuation routes and relocate to reception areas? This is linked with the trust of people in information and to those delivering this information;

- exercises and drills at local level with the involvement of all services, institutions (schools, hospitals, nursing homes, etc.) and population are not organized regularly;

- desk exercises are implemented by competent authorities but with only few field exercises. The response in real environment is not practiced;

- there are no agreements for providing some services foreseen in the EP \& R plans, like the use of mobile units for radiological accidents. Also, the number of experts who could perform such services is very often limited in the country (lack of capacity);

- the food security measures are seen as particularly challenging, as it is very difficult to harmonise the reference levels and other limitations, also due to export and import of products, and this would be a big source of uncertainties;

- communication with the public (general and local) and with media would present a big source of uncertainty: there would be a variety of sources of information including social media, also those with wrong information, which could be source of panic and chaos.

\subsection{Lay models-summary of findings}

Figure 1 summarizes how lay people understand measures to manage nuclear or radiological emergency situations. To sum up, the participants have a general idea of the basic elements of EP \& R plans, but only vague knowledge of each specific protective measure.

Interestingly, interviewees in general differentiate two possible situations in case of an accident at a nuclear power plant: a major or a minor accident. In case of a major accident, it is predominantly believed that nothing would help. They imagine a scenario of many deaths and devastation, and they do not see the real usefulness of EP \& R plans in such a situation. This model is linked with the misconceptions of the effects of ionizing radiation to humans, as many believe that nothing can be done and that the effects of ionizing radiation would be fatal. In case of a minor accident, they believe that there would be radiation contamination and impact on humans, but the emergency plans would be useful.

The memory of major nuclear accidents in Fukushima and Chernobyl is still present today and defines the models people have in relation to a nuclear accident. They consider that similar accidents would have a major impact with dangerous consequences, bringing fear and dread across the borders of the accident country, even to all continents. The consequences would stay for very long periods and could impact the whole lifetime of several generations. In addition, the number of deaths is believed to be high and the trust in reporting by governments is low. People believe that there is no sufficient and relevant available information for the population and that the responsible authorities communicate poorly with the public. In addition, there is also evidence of distrust in the competent and responsible authorities which make the communication even more difficult. On the other hand, interviewees state that too much and too intensive communication could increase the concerns and could lead to panic and chaos.

Some uncertainties and disagreements related with the emergency plans were highlighted by participants:

- What information should be available? Currently, it is not clear what information is available and what should be known by all. Communication should be implemented, including also on social media and other alternatives (like citizens science and measurements). In addition, there should be exercises performed at all levels: local and national;

- What to do? Some people would not follow the instructions as they do not trust the government and institutions. There would be panic and as they feel they are not "really informed", they would alone decide what to do (like selfevacuation);

- Are plans harmonised with the behaviour of the population? There is a question if plans could foresee the real 


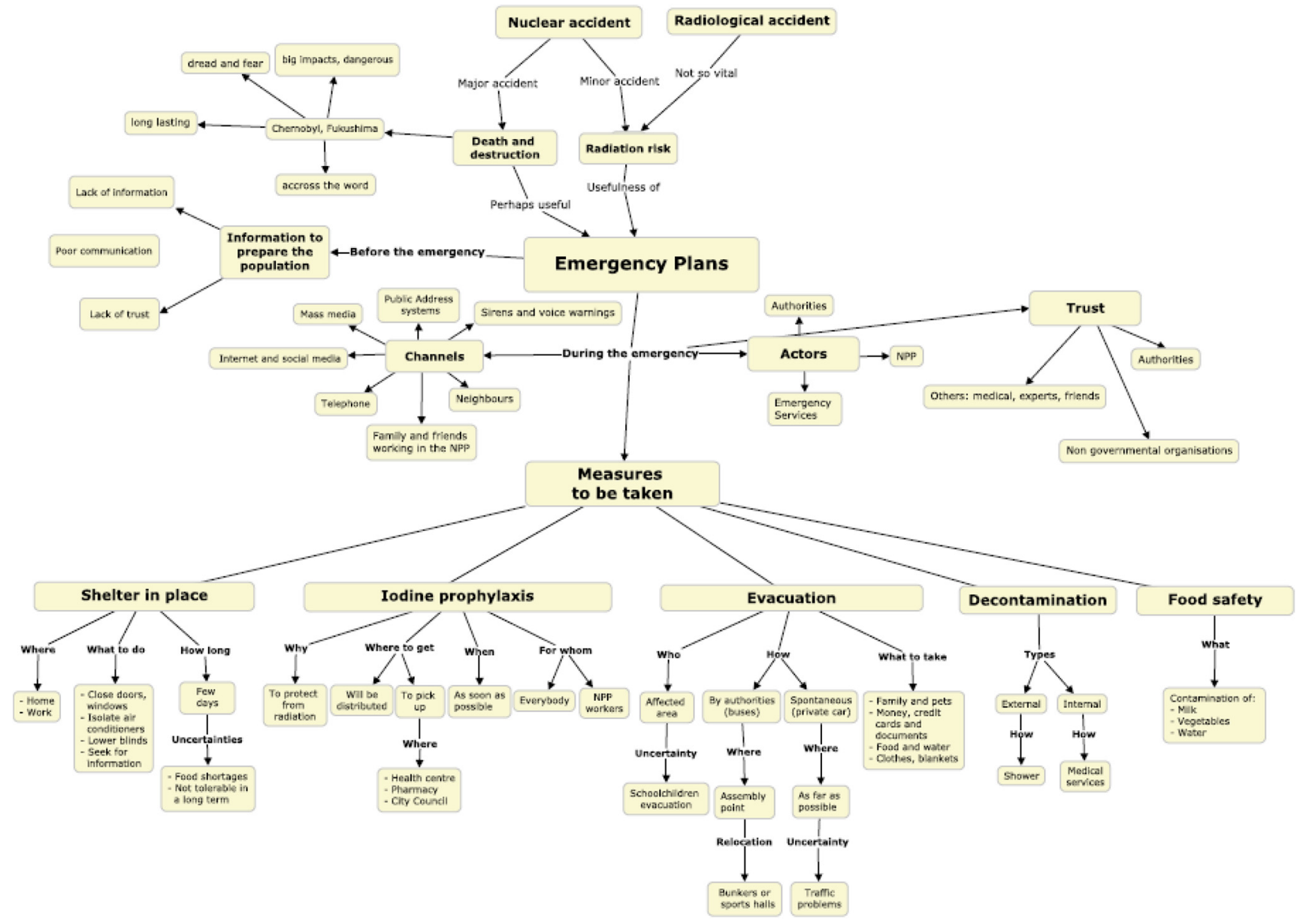

Fig. 1. Mental model of lay public in relation to emergency management.

behaviour of citizens. Some areas of disagreement were pointed out (children in schools and kindergartens, selfevacuation);

- What risks will they face? The associated risk is assessed as very high and some elements of fatalism are present ("nothing can be done").

According to these research findings, the participants seem to have the following ideas about the protective measures in case of a nuclear or radiological emergency: regarding sheltering they think they would be confined inside (for instance, at home or at work) and they would have to be there for many days. Some protective measures, such as to closed doors and windows or to isolate air conditioners, were mentioned. Some images exist that such shelters should be underground bunkers with thick concrete walls. The main uncertainty is whether they would have enough food and drink.

Regarding the measure of evacuation, a clear difference between evacuation ordered and coordinated by authorities and spontaneous or private evacuation can be seen. It is believed that in case of coordinated evacuation probably buses would be used to avoid traffic problems; and that assembly points would be used to gather people. If the evacuation is spontaneous, private cars would be used. Participants think that the implementation of evacuation measures would affect the whole region or even more. They would take mainly money, credit cards and documentation, food and water, and clothes; and, of course, their family and pets. The evacuation of schoolchildren is mentioned as an important uncertainty.

Accommodation and relocation would also be different in case of spontaneous versus advised evacuation. In case of advised evacuation, participants imagine they would be confined in bunkers or in sport halls. In case of spontaneous evacuation, they would go as far as possible, to a second residence if possible or even abroad.

In general, participants have very little knowledge about iodine prophylaxis, and they do not know what the tablets are used for. An important uncertainty is where to get iodine tablets in case of a nuclear emergency. In the same sense, interviewees have very limited knowledge of decontamination. Only some participants relate it with having a shower if the contamination is external or with the need for medical care if the contamination is internal.

Participants believe that milk, vegetables and water would be affected in case of accident, but they do not have any idea of what food measures would be taken.

Nevertheless, even if there is significant awareness that in case of an accident it would be better to comply with governmental instructions, following the instructions is not clear for all the interviewees. It is linked with a lack of trust in the responsible authorities. The main uncertainties mentioned would be what to do, where to go, and how would they be 
informed. Nevertheless, some of the participants would prefer to trust others, like non-governmental organisations, medical doctors, experts and scientists.

Some stakeholders are mentioned as reliable sources of information during an emergency: NPP managers, authorities (both local and regional) and emergency services (Police, Firemen, Civil Protection). Also, some other channels are mentioned: sirens and other systems, mass media, the internet, telephone, neighbours, family and friends working in the NPP.

\section{Suggestions for EP \& R improvement}

The analysis of the interviews resulted in several suggestions which are in line with concluding remarks given in Lochard et al. (2019) that could be taken into account for the improvement of EP \& R planning. Due to the lack of familiarity with and the knowledge of emergency plans there should be more information regarding the EP \& R plans: a public information campaign could include the development of information material (like leaflets, Q\&A sheets) and outreach activities. The involvement of local authorities shall be considered in order to increase the impact of this campaign at the local level, where it is needed. Tailored information and education campaigns addressed to the local community would be, if possible, linked to emergency preparedness measures for other types of emergencies, like earthquakes and fire accidents, and evacuation drills in companies, districts and schools.

Risk communication activities shall take into account the national (radiological) threat assessment. The risk perception and related fear shall be also addressed. The memories about the restrictions people faced for a while after nuclear accidents could serve as a basis for collective thinking, and the development of a story "What might happen if a similar nuclear accident happens here at the nuclear power plant...?" The public awareness of existing risks might be increased, and discussions could be facilitated.

The need for a better understanding of the protection measures that are usually taken in case of a radiological/ nuclear emergency is clear. Modern approaches to public information could include audio-visual material (e.g. video), social media or different mobile applications explaining the main protection measures. During emergency response exercises emphasis shall be given to the aspect related with the implementation of protection measures. Actions needed shall be discussed among the bodies involved in the implementation of EP \& $\mathrm{R}$ plans.

Clarification regarding the roles of different emergency response players in the field of public information can be pursued through the organization of stakeholders' panels and regular emergency response exercises. Authorities in charge of public information during emergencies shall become more visible i.e. by means of information campaigns, media interviews, etc. Resources shall be available in order to support the intense needs of information during emergencies. The access to information about countermeasures for the public should be improved by using all available channels, like the social media, specialized apps for catastrophes and internet sources. Trustworthy organizations shall be used effectively in order to convey crucial information to the public.

\section{Conclusions}

A mental model approach was conducted to investigate and compare experts' and lay peoples' sense-making of uncertainties related to emergency preparedness and response. The research was conducted in five countries: Germany, Greece, Slovak Republic, Slovenia and Spain. It focused on how plans are developed including what is the associated risk, what are the typical elements and what protective measures are foreseen. In addition, the issues of information, notification and trust were analysed.

While experts assume that the EP \& R plan is a tool for risk management and mitigation in any situation, in most countries lay respondents stated not to know much about it and expressed doubts on the effectiveness and usefulness of an EP \& R plan. In general, they believe that the EP \& R plans could function in case of a minor accident i.e. when the expected radiological impacts are small and limited. In case of major accidents, the EP \& R plans are perceived as less useful, since it is widely believed that the radiological consequences would be fatal, and nothing can be done to protect people's lives. Such an attitude is attributed to the present memories of the accidents in Fukushima and Chernobyl, and is also linked to the misconception of impact of ionizing radiation on humans. Knowledge about protective measures exists in general terms among all publics in the countries investigated, but it is particularly limited in the case of iodine tablets use. Respondents were uncertain about their use, the location or means of distribution in case of an accident. Some protection measures such as who will take care for children in case of nuclear emergency are not well supported by the public.

There was also uncertainty about how the public would be informed about the accident and the necessary protective measures. The sources that the public in different countries would consult the most include information provided by public authorities, but also those given by NGO's and other trusted and widely known groups. The landscape of available information would be extremely broad, which would present an additional challenge for emergency management.

Acknowledgement. This paper builds on the open-access CONFIDENCE project deliverable D9.27. CONFIDENCE is part of the H2020 CONCERT project. This project received funding from the EURATOM research and training programme 2014-2018 under grant agreement No. 662287.

Disclaimer (Art. 29.5 GA). This publication reflects only the author's view. Responsibility for the information and views expressed therein lies entirely with the authors. The European Commission is not responsible for any use that may be made of the information it contains.

\section{References}

IAEA. 2015. Preparedness and response for a nuclear or radiological emergency. IAEA Safety Standards Series No. GSR Part 7. Vienna: IAEA.

Lochard J, Schneider T, Ando R, Niwa O, Clement C, Lecomte JF, Tada JI. 2019. An overview of the dialogue meetings initiated by 
ICRP in Japan after the Fukushima accident. Radioprotection 54 (2): $87-101$

Morgan MG, Fischoff B, Bostrom A, Atman CJ. 2002. Risk communication: A mental models approach. Cambridge (UK): Cambridge University Press.

Raskob W, Beresford NA, Duranova T, Korsakissok I, Mathieu A, Montero M, Müller T, Turcanu C, Woda C. 2020. CONFIDENCE:
Project description and main results. Radioprotection 55(HS1). https://doi.org/10.1051/radiopro/2020008.

Zeleznik N, Zorko B, Benighaus L, Benighaus C, Renn O, Tafili V, Mitrakos D, Duranova T, Sala R, Germán S, López-Asensio S, Oltra C. 2019. Identification of mental models of uncertainty management in emergency situations. CONCERT deliverable 9.27. Available from https://www.concert-h2020.eu/en/Publications.

Cite this article as: Zeleznik N, Benighaus L, Mitrakos D, Tafili V, Duranova T, Sala R, Benighaus C. 2020. Mental models in nuclear emergency management. Radioprotection 55(HS1): S157-S162 